\title{
Income and total expenditure on health in OECD countries: Evidence from panel data and Hsiao's version of Granger non-causality tests
}

\author{
Arshia Amiri ${ }^{* *}$ Mikael Linden ${ }^{2}$ \\ ${ }^{1}$ Department of Health and Social Management, University of Eastern Finland, Finland \\ ${ }^{2}$ Department of Law, University of Eastern Finland, Finland
}

Received: 5 July 2015

Revised: 12 November 2015

Accepted: 17 December 2015

\begin{abstract}
Panel data and Hsiao's version of Granger non-causality tests are used to revisit the relationship between GDP and aggregate health care spending, their growth rate series and detrended series. The possible causality is assumed to be valid in either or in both directions. For the sample of 34 OECD countries tested over the period 1970-2012, it appears that the bilateral relationship is predominant in sample countries. Interestingly, our results show evidence with Hsiao method based on final prediction error (FPE) that the lag length of relationship between health care expenditure and GDP is much higher that is found in previous empirical studies. The lag length is around 8 . We consider this as an additional merit of the method as it helps us to avoid some inference problems with series being co-integrated or having different orders of integration.
\end{abstract}

Keywords: health care expenditure; GDP; Granger non-causality test; OECD JEL Classification Codes: I10, I18

\section{Introduction}

Since the pioneering surveys proposed by Kleiman (1974) and Newhouse (1977), majority of studies agree that most of the variation in health care expenditure $(H C E)$ can be related to variation in national income and GDP. Prominently aggregate health spending is a function of $G D P$ (see Hansen and King 1996). In fact, GDP is the only robust explanatory variable for $H C E$ that the health economics literature has been able to uncover so far (Hartwig, 2008). Studies with support that income leads to $H C E$ include but are not limited to Newhouse

\footnotetext{
* Corresponding author. E-mail: arshia.amiri@uef.fi.

Citation: Amiri, A. and Linken, M. (2016) Income and total expenditure on health in OECD countries: Evidence from panel data and Hsiao's version of Granger non-causality tests, Economics and Business Letters, 5(1), 1-9.
} 
(1987), Cullis and West (1979), Leu (1986), Parkin et al. (1987), Culyer (1990), Milne and Molana (1991), Gerdtham and Jonsson (1991a, 1991b), Hitiris and Posnett (1992), Murthy and Ukpolo (1994), McCoskey and Selden (1998), Roberts (1998), Gerdtham and Lothgren (2000), Jewell et al. (2003) and Carrion-i-Silvestre (2005).

On the other hand, the theory of economic growth posits that GDP is a function of human capital services, and health has been known for long to be an important element of the human capital stock (see Schultz, 1961; Mushkin, 1962). Increasing health level prepares better conditions for labors to work longer and to be more productive. This leads to increases in income, welfare, and in economic growth (Weil 2009; Amiri and Ventelou, 2012). A number of articles, including Bloom and Canning (2000), Kalemli-Ozcan et al. (2000), reviewed in Hartwig (2010) have found a significantly positive impact of investment in health on GDP growth.

From a theoretical point of view, the relationship between $H C E$ and GDP is likely to run in both directions. Devlin and Hansen (2001), Erdil and Yetkiner (2009), and Amiri and Ventelou (2012) have used the concept of Granger causality to test this. Devlin and Hansen find causal direction running for 8 OECD countries from GDP to $H C E$ and 8 from $H C E$ to GDP out of 20 OECD countries in an annual sample for the period of 1960 to 1987. Erdil and Yetkiner's sample covers 75 countries on different income levels for the period of 1990 to 2000. They find bi-directional relationship for 46 countries, unidirectional relationship from $G D P$ to $H C E$ for 12 and from $H C E$ to GDP for 10. Amiri and Ventelou (2012) use the TodaYamamoto version of Granger non-causality test (Toda and Yamamoto, 1995) for OECD countries. They find 10 bilateral and 9 from $G D P$ to $H C E$ relationships out of 20 OECD countries during the 1970-2009 period.

As a conclusion, pervious literature suggests that relationship between $H C E$ and GDP can be defined in either or in both directions. This study recalculates for the presence and direction of Granger causality between $H C E$ and GDP using panel non-causality test and a novel version of Granger test proposed by Hsiao (1981) for a selection of 34 OECD countries.

The deficiency of the ordinary Granger non-causality test is that it lacks "theoretical justification in assuming that two or more related variables must have identical predetermined lag lengths" (Cheng and Lai, 1997). To correct this shortcoming in previous empirical studies Hsiao's approach is used in this context. Furthermore, for the reason of testing high lag lengths in Hsiao's version of Granger method ${ }^{1}$ compared with other approaches have been unable until now because of the lack of available health expenditure data for many countries.

\section{Data description}

$G D P$ per capita data was derived from growth rates of main income accounts (c, g, i) at 2005 PPP converted constant prices. It was collected from Penn World Tables 7.1 (Heston et al. 2012), The World Bank IBRD-IDA (2015) database as well as from the UN database (2014). Health spending data (as share of $G D P$ ) for OECD countries were taken from OECD.org (2015). These sources gave possibility calculate the annual observations of (logs of) GDP per capita $(\ln G D P c)$ and $\operatorname{logs}$ of $H C E$ per capita $(\ln H C E c)$ for the following 34 OECD countries in period from 1970 to 2012: Australia, Austria, Belgium, Canada, Chile, Czech Republic, Denmark, Estonia, Finland, France, Germany, Greece, Hungry, Iceland, Ireland, Israel, Italy, Japan, Luxemburg, Mexico, Netherland, New Zealand, Norway, Poland, Portugal, Slovakia, Slovenia, South Korea, Spain, Sweden, Switzerland, Turkey, United Kingdom and United States.

\footnotetext{
${ }^{1}$ Lag lengths close to 10 have to be calculated with Hsiao method, and this causes a significant decrease the degree of the freedom of Granger structure.
} 


\section{Panel unit root testing}

The first essential step in the analysis is unit root testing. The order of integration of test series modifies non-causality testing (see Lutkepohl 2005; Section 7.6.) In this context we conducted unit root test in panel form to get a general view of stationarity properties of series in efficient way. Various panel tests were applied to investigate the stationary of $\ln G D P c$ and $\ln H C E c$ series, their growth rates, and their de-trended ${ }^{2}$ transformations. Different test have been proposed in the literature, and we use here the $A D F$-type tests by Levin et al. (2002) and Im et al. (2003), and Fisher tests by Maddala and Wu (1999). Result unit root tests verify strong evidence that panel of both $\ln G D P c$ and $\ln H C E c$ series are stationary with individual mean and trend components. Likewise growth rates series and de-trended series are stationary (see Table 1).

\section{Panel Granger non-causality testing}

Based on the stationary results of unit root tests we are able to test Granger non-causality without test modifications needed with non-stationary series. Table 2 present the result of panel Granger non-causality tests for $\ln G D P c$ and $\ln H C E c$, their growth rates, and de-trended series. We conduct the Granger non-causality test in two different forms (Eviews, 2012). The first is to treat the panel data as one large stacked set of data, and then perform the pairwise Granger non-causality test in the standard way $\left(\mathrm{GC}_{1}\right.$-test). This method assumes that all coefficients are same across all cross-sections. A second approach adopted by Dumitrescu and Hurlin (2012) allows all coefficients to be different across cross-sections ( $\mathrm{GC}_{2}$-test). The test is calculated by running standard Granger causality regressions for each cross-section individually. Wbar statistic is based on the average of these test statistics, and Zbar statistic is the Normal standardized version of this statistic.

Results in Table 2 show that the direction of causality between $\ln G D P c$ and $\ln H C E c$ is bilateral and in growth rates it is from $\triangle \ln G D P c$ to $\triangle \ln H C E \mathrm{c}$. For the de-trended series the result of panel Granger non-causality tests are different. $\mathrm{GC}_{1}$-test gives bilateral causality and $\mathrm{GC}_{2}$-test supports $\ln G D P c_{-}$detr $\rightarrow$ InHCEc_detr relationship. This non-consistency result compared to results with growth rate series directs us to investigating Granger non-causality for each country in sample separately. This is conducted with Hsiao's version of Granger noncausality test that is based on minimization of FPE-criterion.

Table 1. Panel unit root test. $\mathrm{H}_{0}$ : unit root.

\begin{tabular}{|c|c|c|c|c|}
\hline \multirow{3}{*}{ Exogenous variables } & \multicolumn{2}{|l|}{$\operatorname{lnGDPc}$} & \multicolumn{2}{|c|}{$\operatorname{lnGDPc}$} \\
\hline & \multicolumn{2}{|c|}{ Individual effects, individual linear trends } & \multicolumn{2}{|c|}{ Individual effects } \\
\hline & Statistic & Probability & Statistic & Probability \\
\hline Levin, Lin \& Chu $t^{*}$-test & -3.08253 & 0.0010 & -6.101 & 0.0000 \\
\hline Im, Pesaran and Shin W-stat & -2.75023 & 0.0030 & 1.11878 & 0.8684 \\
\hline ADF - Fisher Chi-square & 102.360 & 0.0045 & 67.2408 & 0.5032 \\
\hline PP - Fisher Chi-square & 206.263 & 0.0000 & 110.409 & 0.0009 \\
\hline \multirow{3}{*}{ Exogenous variables } & $\Delta \operatorname{lnGDPc}$ & & lnGPc_de & \\
\hline & \multicolumn{2}{|c|}{ Individual effects } & None & \\
\hline & Statistic & Probability & Statistic & Probability \\
\hline Levin, Lin \& Chu t*-test & -24.8483 & 0.0000 & -7.61102 & 0.0000 \\
\hline Im, Pesaran and Shin W-stat & -23.3024 & 0.0000 & & \\
\hline ADF - Fisher Chi-square & 594.034 & 0.0000 & 167.524 & 0.0000 \\
\hline PP - Fisher Chi-square & 607.213 & 0.0000 & 158.358 & 0.0000 \\
\hline
\end{tabular}

\footnotetext{
${ }^{2}$ De-trended transformation of $\ln X$ is the residuals from fixed effect panel regression $\ln X_{i t}=a_{i}+b T R E N D_{t}+e_{i t}$.
} 


\begin{tabular}{|c|c|c|c|c|}
\hline \multirow{3}{*}{ Exogenous variables } & \multicolumn{2}{|l|}{$\operatorname{lnHCEc}$} & \multicolumn{2}{|l|}{$\operatorname{lnHCEc}$} \\
\hline & \multicolumn{2}{|c|}{ Individual effects, individual linear trends } & \multicolumn{2}{|c|}{ Individual effects } \\
\hline & Statistic & Probability & Statistic & Probability \\
\hline Levin, Lin \& Chu t*-test & -4.09263 & 0.0000 & -8.54981 & 0.0000 \\
\hline Im, Pesaran and Shin W-stat & -2.53026 & 0.0057 & -0.56195 & 0.2871 \\
\hline ADF - Fisher Chi-square & 120.866 & 0.0001 & 123.529 & 0.0000 \\
\hline PP - Fisher Chi-square & 213.812 & 0.0000 & 150.203 & 0.0000 \\
\hline \multirow{3}{*}{ Exogenous variables } & \multicolumn{2}{|l|}{$\triangle \operatorname{lnHCEc}$} & \multicolumn{2}{|c|}{ lnHCEc_detr } \\
\hline & \multicolumn{2}{|c|}{ Individual effects } & \multicolumn{2}{|c|}{ None } \\
\hline & Statistic & Probability & Statistic & Probability \\
\hline Levin, Lin \& Chu t*-test & -23.5967 & 0.0000 & -6.58659 & 0.0000 \\
\hline Im, Pesaran and Shin W-stat & -22.3941 & 0.0000 & & \\
\hline ADF - Fisher Chi-square & 567.482 & 0.0000 & 200.503 & 0.0000 \\
\hline PP - Fisher Chi-square & 608.140 & 0.0000 & 219.441 & 0.0000 \\
\hline
\end{tabular}

Note: Probabilities for all tests except Fisher tests, which have Chi-square distribution, are calculated using an asymptotic normality assumption.

Table 2. Panel Granger non-causality tests.

\begin{tabular}{|c|c|c|c|c|}
\hline$G C_{1}$-test: & & F-Stat. & Probability & Direction \\
\hline lnHCEc does not Granger Cause lnGDPc & & 16.3336 & $1.00 \mathrm{E}-07 *$ & \multirow{2}{*}{ Bilateral } \\
\hline lnGDPc does not Granger Cause lnHCEc & & 34.6590 & $2.00 \mathrm{E}-15^{*}$ & \\
\hline GC2-test: & W-Stat. & Zlbar-Stat. & Probability & Direction \\
\hline lnHCEc does not homogeneously cause lnGDPc & 4.56860 & 6.36273 & $2.00 \mathrm{E}-10^{*}$ & \multirow{2}{*}{ Bilateral } \\
\hline lnGDPc does not homogeneously cause lnHCEc & 9.73660 & 19.7790 & $0.00 *$ & \\
\hline GC & & F-Stat. & Probability & Direction \\
\hline$\Delta \operatorname{lnHCEcn}$ does not Granger Cause $\Delta \operatorname{lnGDPc}$ & & 0.09783 & 0.9068 & \multirow{2}{*}{$\begin{array}{l}\Delta \operatorname{lnGDPc} \rightarrow \\
\Delta \operatorname{lnHCEc}\end{array}$} \\
\hline$\Delta \operatorname{lnGDPc}$ does not Granger Cause $\triangle \ln H C E c$ & & 5.96122 & $0.0026^{*}$ & \\
\hline GC $C_{2}$-test: & $W$-Stat. & Zbar-Stat. & Probability & Direction \\
\hline$\Delta \operatorname{lnHCEc}$ does not homogeneously cause $\Delta \operatorname{lnGDPc}$ & 2.02033 & -0.26099 & 0.7941 & \multirow{2}{*}{$\begin{array}{l}\Delta \operatorname{lnGDPc} \rightarrow \\
\Delta \operatorname{lnHCEc}\end{array}$} \\
\hline$\triangle \operatorname{lnGDPc}$ does not homogeneously cause $\triangle \ln H C E c$ & 5.00614 & 7.46342 & $8.00 \mathrm{E}-14 *$ & \\
\hline GC $C_{1}$-test: & & F-Stat. & Probability & Direction \\
\hline lnHCEc_detr does not Granger Cause lnGDPc_detr & & 2.20033 & 0.1112 & \multirow{2}{*}{$\begin{array}{l}\text { lnGDPc_det } \rightarrow \\
\text { lnHCEc_detr }\end{array}$} \\
\hline lnGDPc_detr does not Granger Cause lnHCEc_detr & & 19.8856 & $3.00 \mathrm{E}-09^{*}$ & \\
\hline GC2-test: & W-Stat. & Zbar-Stat. & Probability & Direction \\
\hline $\begin{array}{l}\text { lnHCEc_detr does not homogeneously cause } \\
\text { lnGDPc_detr }\end{array}$ & 2.93983 & 2.13440 & $0.0328 *$ & \multirow[t]{2}{*}{ Bilateral } \\
\hline lnGDPc_detr does not homogeneously cause lnHCEc_detr & 7.16536 & 13.1040 & $0.00 *$ & \\
\hline
\end{tabular}

Note: Maximum lag length is 2.* means that null hypothesis is rejected.

\section{Hsiao's version of Granger causality test}

Hsiao (1981) offered final prediction error (FPE) criterion to estimate the optimum lag length of Granger's test structure. The procedure of the Hsiao method ${ }^{3}$ implements the testing null hypothesis of $H C E$ does not Granger cause GDP in the following way. In the first step we use $\ln G D P c_{-}$detr $r_{t}$ alone (the restricted equation) and calculate the sum of squared errors (SSE) for each lags from 1 to maximum order of lags $M$. With finding SSE for various lags the FPE is computed using equation (2). Next we are able to choose the optimum lag length which corresponds to the smallest value of $F P E$, i.e. $m^{*} \leq M(T$ is the total number of observations in the sample).

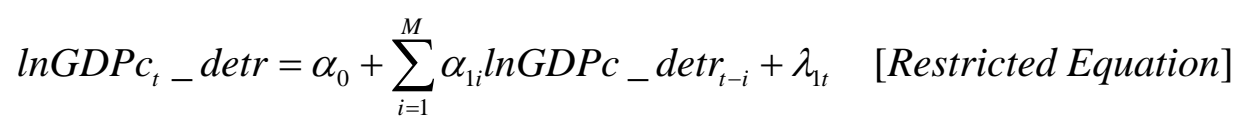

\footnotetext{
${ }^{3}$ In order to explain Hsiao version of Granger non-causality test we refer directly to paper by Cheng and Lai (1997, pp. $21-22)$.
} 


$$
\operatorname{FPE}(m)=\frac{(T+m+1)}{(T-m-1)} \cdot \frac{S S E}{T}
$$

In the following step two, $\ln G D P c_{-}$detr $t_{t}$ is used in unrestricted equation (3) as a control variable with $m^{*}$ lags and $l n H C E c \_d e t r_{t}$ is treated as a manipulated variable. The procedure is same as above but now the focus is on the unrestricted equation (3). We iterate for the smallest FPE value using equation (4) by varying the order of lags for $I n H C E c_{-}$detr ${ }_{t}$ from 1 to $N$ giving $n^{*}$.

$$
\begin{gathered}
\ln G D P c_{t-} \operatorname{detr}_{t-i}=\beta_{0}+\sum_{i=1}^{m^{*}} \beta_{1 i}{\ln G D P c_{-} \text {detr }_{t-i}}_{\text {[Unrest }} \\
+\sum_{j=1}^{N} \beta_{2 j} \ln H C E c_{-} \text {detr }_{t-j}+\lambda_{2 t} \\
\operatorname{FPE}(m *, n)=\frac{\left(T+m *+n^{*}+1\right)}{\left(T-m *-n^{*}-1\right)} \cdot \frac{\operatorname{SSE}\left(m *, n^{*}\right)}{T}
\end{gathered}
$$

The Hsiao version of Granger test with null hypothesis of $l n H C E c_{-}$detr $r_{t}$ does not Granger cause $\ln G D P c_{-}$detr $t_{t}$ can be now formulated: If $\operatorname{FPE}\left(m^{*}, n^{*}\right)$ is less than $F P E\left(m^{*}\right)$, then the null hypothesis of non-causality is rejected. Conversely, if $\operatorname{FPE}\left(m^{*}, n^{*}\right)$ is larger than $F P E\left(m^{*}\right)$, then the null hypothesis cannot be rejected. The procedure is same for estimating Granger test from $\ln G D P c_{-}$detr $r_{t}$ to $l n H C E c_{-}$detr . Note that Hsiao's method is not a statistical test. It is procedure based on FPE to determine the optimal lag length. In this sense it is not sensitive to inference problems found with ordinary Granger non-causality tests in presentence of integrated series.

\section{Result of Hsiao's Granger non-causality test}

Appendix A gives the ordinary $A D F$-unit root test results with constant and trend for each country in sample. Here the optimal lag length for $A D F$-test is determined with Schwarz information criteria $(S I C)$. We observe that $S I C$ gives different lag lengths to series $\ln G D P c_{-}$detr and $\ln H C E c \_$detr. Likewise the $A D F$-test values indicate that in many cases the country specific series have different orders of integration or they are both $I(1)$ series. Clearly we have here a valid starting point for Hsiao's method.

In order to estimate Granger causality, Hsiao's version of Granger non-causality test was estimated with three to ten lags with the FPE criterion. The results of Hsiao's method confirm (see Table 3) bidirectional relationship between $\operatorname{lnHCEC\_ detr}$ and $\ln G D P c_{-}$detr for most countries. In 18 countries (53\% of the total), we find that the direction of relationship to be bilateral. This result could suggest that the role of $H C E$ on GDP increases with the wealth of nations (see Bloom and Canning, 2000). However, we find a unidirectional relationship from InHCEc_detr to InGDPc_detr only for 3 countries; Belgium, Chile and Poland. There exists $\ln G D P c_{-}$detr $\rightarrow$ InHCEc_detr relationship in 9 counties included Austria, Canada, Czech Republic, Denmark, Greece, Hungry, Japan, Norway, and Spain. In Luxemburg, Mexico, Slovakia, and Turkey we find no significant relationship between lnHCEc_detr and $\ln G D P c_{-}$detr. More interestingly, the FPE results show that the optimum lag length of the relationship between $G D P$ and $H C E$ is dramatically higher than previously estimated, and it is around 8. 
Table 3. Result of Hsiao Granger causality test.

\begin{tabular}{|c|c|c|c|c|c|}
\hline \multirow{3}{*}{ Countries } & \multicolumn{4}{|c|}{ Lowest FPE \& lag length } & \multirow{3}{*}{ Direction } \\
\hline & \multicolumn{2}{|c|}{$\ln G D P c \_d e t r$ to $l n H C E c \_d e t r$} & \multicolumn{2}{|c|}{ InHCEc_detr to lnGDPc_detr } & \\
\hline & Unrestricted & Restricted & Unrestricted & Restricted & \\
\hline Australia & $0.173(10)$ & $0.148^{*}(5)$ & $0.144(10)$ & $0.040 *(10)$ & Bilateral \\
\hline Austria & $1.623(7)$ & $1.218 *(10)$ & $0.191(9)$ & $0.221(3)$ & lnGDPc_detr $\rightarrow$ lnHCEc_detr \\
\hline Belgium & $0.569(6)$ & $0.609(10)$ & $0.285(10)$ & $0.147 *(7)$ & lnHCEc_detr $\rightarrow \operatorname{lnGDPc}$ detr \\
\hline Canada & $0.335(6)$ & $0.249 *(10)$ & $0.456(3)$ & $0.499(3)$ & lnGDPc_detr $\rightarrow \operatorname{lnHCEc\_ detr}$ \\
\hline Chile & $1.292(6)$ & $1.431(3)$ & $2.111(7)$ & $2.110 *(7)$ & lnHCEc_detr $\rightarrow$ lnGDPc_detr \\
\hline Czech Republic & $2.884(5)$ & $1.247 *(10)$ & $6.986(5)$ & $7.568(5)$ & lnGDPc_detr $\rightarrow$ lnHCEc_detr \\
\hline Denmark & $0.580(10)$ & $0.464 *(3)$ & $0.604(10)$ & $0.652(9)$ & lnGDPc_detr $\rightarrow$ lnHCEc_detr \\
\hline Estonia & $0.801(8)$ & $0.453 *(9)$ & $2.205(3)$ & $1.534 *(9)$ & Bilateral \\
\hline Finland & $0.803(6)$ & $0.279 *(10)$ & $1.231(4)$ & $1.185 *(3)$ & Bilateral \\
\hline France & $0.513(10)$ & $0.499 *(10)$ & $0.208(10)$ & $0.186 *(3)$ & Bilateral \\
\hline Germany & $0.374(9)$ & $0.325^{*}(10)$ & $0.364(9)$ & $0.325^{*}(10)$ & Bilateral \\
\hline Greece & $2.979(3)$ & $2.863 *(3)$ & $0.598(5)$ & $0.602 *(9)$ & lnGDPc_detr $\rightarrow$ lnHCEc_detr \\
\hline Hungary & $1.971(3)$ & $1.890 *(8)$ & $0.822(3)$ & $0.898(9)$ & lnGDPc_detr $\rightarrow$ lnHCEc_detr \\
\hline Iceland & $1.995(8)$ & $1.945^{*}(3)$ & $2.687(10)$ & $2.421 *(4)$ & Bilateral \\
\hline Ireland & $1.531(10)$ & $0.558 *(10)$ & $1.686(3)$ & $1.191 *(10)$ & Bilateral \\
\hline Israel & $3.894(10)$ & $3.113 *(10)$ & $0.656(7)$ & $0.450 *(10)$ & Bilateral \\
\hline Italy & $0.571(3)$ & $0.524 *(8)$ & $0.533(10)$ & $0.428 *(9)$ & Bilateral \\
\hline Japan & $0.192(9)$ & $0.078 *(10)$ & $0.607(6)$ & $0.692(3)$ & lnGDPc_detr $\rightarrow$ lnHCEc_detr \\
\hline Luxembourg & $3.288(3)$ & $3.678(5)$ & $0.620(10)$ & $0.703(3)$ & No \\
\hline Mexico & $1.307(6)$ & $1.365(3)$ & $1.857(10)$ & $1.960(3)$ & No \\
\hline Netherlands & $0.435(9)$ & $0.369^{*}(10)$ & $0.240(10)$ & $0.147 *(9)$ & Bilateral \\
\hline New Zealand & $0.776(9)$ & $0595 *(10)$ & $0.245(7)$ & $0.204 *(7)$ & Bilateral \\
\hline Norway & $1.409(6)$ & $0.457 *(10)$ & $0.322(3)$ & $0.334(3)$ & lnGDPc_detr $\rightarrow$ lnHCEc_detr \\
\hline Poland & $1.368(8)$ & $1.379(3)$ & $1.463(10)$ & $1.049^{*}(10)$ & lnGDPc_detr $\rightarrow$ lnGDPc_detr \\
\hline Portugal & $2.745(10)$ & $1.996 *(8)$ & $0.440(8)$ & $0.355^{*}(10)$ & Bilateral \\
\hline Slovakia & $585.849(3)$ & $671.948(3)$ & $5.688(5)$ & $6.479(3)$ & No \\
\hline Slovenia & $0.689(10)$ & $0.668 *(3)$ & $1.198(5)$ & $0.743 *(10)$ & Bilateral \\
\hline South Korea & $1.809(5)$ & $1.587 *(9)$ & $1.950(10)$ & $1.536 *(10)$ & Bilateral \\
\hline Spain & $1.154(10)$ & $0.535^{*}(10)$ & $0.324(7)$ & $0.361(3)$ & lnGDPc_detr $\rightarrow$ lnHCEc_detr \\
\hline Sweden & $0.340(9)$ & $0.300 *(10)$ & $0.497(10)$ & $0.449 *(6)$ & Bilateral \\
\hline Switzerland & $0.269(10)$ & $0.200 *(5)$ & $0.244(10)$ & $0.234 *(10)$ & Bilateral \\
\hline Turkey & $9.313(10)$ & $9.830(3)$ & $1.549(9)$ & $1.622(10)$ & No \\
\hline United Kingdom & $0.537(10)$ & $0.437 *(5)$ & $0.329(10)$ & $0.307 *(3)$ & Bilateral \\
\hline United States & $0.089(9)$ & $0.056 *(10)$ & $0.450(10)$ & $0.441 *(9)$ & Bilateral \\
\hline
\end{tabular}

Note: * confirms that FPE in unrestricted equation is lower than restricted equation. The numbers in parentheses denotes the optimum lag length.

\section{Conclusions}

There has been much interest in investigating the presence of and the direction of causality between GDP per capita and total health expenditure per capita. From the theoretical point of view, this is a bilateral relationship. To test this, we used first panel Granger non-causality tests to $\ln G D P c$ and $\ln H C E c$ series, to their growth rate series, and to their de-trended series in 34 OECD countries in period from 1970 to 2012. The empirical result of panel Granger non-causality tests indicate that bi-directional causality is dominant between $\ln G D P c$ and $\ln H C E c$ series, while in growth series the relationship is from economic growth to $H C E c$ growth. Moving to de-trended series, result of panel Granger tests were different and needed a closer analysis.

To correct the statistical shortcomings of previous empirical studies, Hsiao's version of Granger non-causality test was applied. The Hsiao's test results indicate that bi-directional causality is widely dominant. Bilateral relationship is observed in more than half of OECD 
countries. This indicates that improvements of human capital in the form of health on GDP are significantly effective in rich countries. Our results also indicate that the optimum lag length of relationship between $H C E c$ and $G D P c$ is higher than estimated in previous empirical studies. This finding alerts research to pay more attention to higher lag lengths in further estimations to avoid specification errors in their models. This is also supported by the theoretical results in the co-integration literature and for series that are of different order of integration. In such contexts it is recommended to add in Granger non-causality tests additional lags to obtain correct asymptotic test distribution results (see Lutkepohl, 2005; Section 7.6). However Hsiao's approach is based on FPE criteria which does not depend on asymptotic distribution results although the method is sensitive to long lag lengths.

\section{References}

Amiri, A. and Ventelou, B. (2012) Granger causality between total expenditure on health and GDP in OECD: Evidence from Toda-Yamamoto approach, Economics Letters, 116, 541-544.

Bloom, D. and Canning, D. (2000) The health and wealth of nations, Science, 287, 12071209.

Cheng, B.S. and Lai, T.W. (1997) Government expenditure and economic growth in South Korea: A VAR approach, Journal of Economic Development, 22 (1), 11-24.

Carrion-i-Silvestre, J.L. (2005) Health care expenditure and GDP: Are they broken stationary?, Journal of Health Economics, 24, 839-854.

Cullis, J.G. and West, P.A. (1979) The economics of health: An introduction, Martin Robertson, Oxford.

Culyer, A.J. (1990) Cost containment in Europe, in: OECD, Health care systems in transition (OECD, Paris), 29-40.

Devlin, N. and Hansen, P. (2001) Health care spending and economic output: Grangercausality, Applied Economics Letters, 8, 561-564.

Dumitrescu, E.-I. and Hurlin, C. (2012) Testing for Granger Non-causality in Heterogeneous Panels, Economic Modeling, 29, 1450-1460.

Erdil, E. and Yetkiner, I.H. (2009) The Granger-causality between health care expenditure and output: A panel data approach, Applied Economics, 41, 511-518.

EViews 8 (2012) IHS Global Inc, NY.

Gerdtham, U.G. and Jonsson, B. (1991a) Price and quantity in international comparisons of health care expenditure, Applied Economics, 23, 1519-1528.

Gerdtham, U.G. and Jonsson, B. (1991b) Conversion factor instability in international comparisons of health care expenditure, Journal of Health Economics, 10, 227-234.

Gerdtham, U.G. and Lothgren, M. (2000) On stationarity and cointegration of international health expenditure and GDP, Journal of Health Economics, 19(4), 461-475.

Hansen, P. and King, A. (1996) The determinants of health care expenditure: A cointegration approach, Journal of Health Economics, 15, 127-137.

Hartwig, J. (2008) What drives health care expenditure? - Baumol's model of 'unbalanced growth' revisited, Journal of Health Economics, 27, 603-623.

Hartwig, J. (2010) Is health capital formation good for long-term economic growth? - Panel Granger-causality evidence for OECD countries, Journal of Macroeconomics, 32, 314-325.

Heston, A., Summers, R. and Aten, B. (2012) Penn World Table Version 7.1, Center for International Comparisons of Production, Income and Prices at the University of Pennsylvania. 
Hitiris, T. and Posnett, J. (1992) The determinants and effects of health expenditure in developed countries, Journal of Health Economics, 11, 173-181.

Hsiao. C. (1981) Autoregressive Modeling and Money Income Causality Detection, Journal of Monetary Economics, 7, 85-106.

Im, K.S., Pesaran, H.M. and Shin, Y. (2003) Testing for Unit Roots in Heterogeneous Panels, Journal of Econometrics, 115, 53-74.

Jewell, T., Lee, J., Tieslau, M. and Strazicich, M.C. (2003) Stationarity of health expenditures and GDP: evidence from panel unit root tests with heterogeneous structural breaks, Journal of Health Economics, 22, 313-323.

Kalemli-Ozcan, S., Ryder, H.E. and Weil, D.N. (2000) Mortality decline, human capital investment, and economic growth, Journal of Development Economics, 62, 1-23.

Kleiman, E. (1974) The determinants of national outlay on health, The Economics of Health and Medical Care, (Ed) M. Perlman, Macmillan, London, pp. 66-81.

Leu, R.R. (1986) The public-private mix and international health care cost, A.J. Culyer and B. Jonsson, eds., Public and private health services: Complementarities and conflicts, Basil Blackwell, Oxford.

Levin, A., Lin, C.F. and Chu, C.S. (2002) Unit root tests in panel data: Asymptotic and finite sample properties, Journal of Econometrics, 108, 1-24.

Lutkepohl, H. (2005) New Introduction to Multiple Time Series Analysis, Springer, Berlin.

Maddala, G.S. and Wu, S. (1999) A Comparative Study of Unit Root Tests with Panel Data and A New Simple Test, Oxford Bulletin of Economics and Statistics, 61, 631-52.

McCoskey, S.K. and Selden, T.M. (1998) Health care expenditures and GDP: panel data unit root test results, Journal of Health Economics, 17(3), 369-376.

Milne, R. and Molana, H. (1991) On the effect of income and relative price on demand for health care: EC evidence, Applied Economics, 23, 1221-1226.

Murthy, N.R.V. and Ukpolo, V. (1994) Aggregate health care expenditure in the United States: evidence from cointegration tests, Applied Economics, 26(8), 797-802.

Mushkin, S.J. (1962) Health as an investment, Journal of Political Economy, 70, 129-157.

Newhouse, J.P. (1977) Medical care expenditure: A cross-national survey, Journal of Human Resources, 12, 115-125.

Newhouse, J.P. (1987) Cross-national differences in health spending: What do they mean?, Journal of Health Economics, 6, 159-162.

OECD.org (2015) http://data.oecd.org/healthres/health-spending.htm\#indicator-chart, retrieved on January 11, 2015.

Parkin, D., McGuire, A. and Yule, B. (I987) Aggregate health care expenditures and national incomes: Is health care a luxury good?, Journal of Health Economics, 6, 109-127.

Roberts, J. (1999) Sensitivity of elasticity estimates for OECD health care spending: analysis of a dynamic heterogeneous data field, Health Economics, 8(5), 459-472.

Schultz, T.W. (1961) Investment in human capital, American Economic Review, 51, 1-17.

Toda H.Y. and Yamamoto, T. (1995) Statistical inference in vector autoregressions with possibly integrated processes, Journal of Econometrics, 66, 225-250.

Weil, D.N. (2009) Economic Growth, 2nd ed. Pearson International, NY.

The World Bank (2015) http://search.worldbank.org/all?qterm=Population+Total\&title $=\&$ filetype $=$, retrieved on February 2, 2015.

United Nations Population Division (UNPD) (2014) http://esa.un.org/unpd/wpp/Excel-Data/ population. htm, retrieved on January 19, 2015. 


\section{Appendix A}

\section{ADF - unit root test for sample countries}

Table 4. ADF: Unit root test for sample countries.

\begin{tabular}{|c|c|c|c|c|c|c|}
\hline Cross section & \multicolumn{3}{|c|}{$\ln G D P c \_$detr } & \multicolumn{3}{|c|}{ lnHCEc_detr } \\
\hline Australia & -3.4487 & 0.0589 & 1 & -3.0151 & 0.1409 & 2 \\
\hline Austria & -3.5095 & 0.0513 & 0 & -1.7079 & 0.7301 & 0 \\
\hline Belgium & -2.9389 & 0.1613 & 0 & -3.0796 & 0.1243 & 0 \\
\hline Canada & -3.3889 & 0.0669 & 1 & -2.2307 & 0.4607 & 1 \\
\hline Chile & -3.1984 & 0.0989 & 1 & -2.6994 & 0.2421 & 0 \\
\hline Czech Republic & -5.0102 & 0.0011 & 0 & -1.9836 & 0.5931 & 0 \\
\hline Denmark & -2.9818 & 0.1495 & 1 & -1.9207 & 0.6261 & 0 \\
\hline Estonia & -2.1561 & 0.5004 & 1 & -1.6865 & 0.7392 & 1 \\
\hline Finland & -3.5070 & 0.0519 & 1 & -2.8584 & 0.1861 & 1 \\
\hline France & -3.2341 & 0.0921 & 1 & -1.6988 & 0.7342 & 0 \\
\hline Germany & -2.1143 & 0.5231 & 0 & -6.4595 & 0.0000 & 0 \\
\hline Greece & -2.0660 & 0.5487 & 1 & -0.9890 & 0.9347 & 0 \\
\hline Hungary & -2.0655 & 0.5490 & 1 & -1.9602 & 0.6055 & 0 \\
\hline Iceland & -2.8544 & 0.1874 & 1 & -1.0489 & 0.9254 & 1 \\
\hline Ireland & -2.0862 & 0.5378 & 1 & -1.7094 & 0.7290 & 1 \\
\hline Israel & -2.8349 & 0.1935 & 0 & -2.6233 & 0.2726 & 0 \\
\hline Italy & -1.1876 & 0.8996 & 2 & -2.4900 & 0.3312 & 1 \\
\hline Japan & -1.0678 & 0.9225 & 0 & -3.0270 & 0.1372 & 0 \\
\hline Luxembourg & -1.8166 & 0.6779 & 2 & -2.2016 & 0.4758 & 2 \\
\hline Mexico & -2.4851 & 0.3335 & 0 & -3.6466 & 0.0380 & 1 \\
\hline Netherlands & -2.4183 & 0.3652 & 1 & -2.0528 & 0.5554 & 2 \\
\hline New Zealand & -2.1305 & 0.5141 & 1 & -1.3912 & 0.8492 & 0 \\
\hline Norway & -2.1334 & 0.5125 & 1 & -2.8410 & 0.1915 & 0 \\
\hline Poland & -1.8083 & 0.6825 & 1 & -1.3602 & 0.8581 & 0 \\
\hline Portugal & -2.2309 & 0.4606 & 1 & -2.8262 & 0.1964 & 0 \\
\hline Slovakia & -2.4657 & 0.3425 & 1 & -6.0754 & 0.0000 & 0 \\
\hline Slovenia & -1.7509 & 0.7099 & 1 & -1.8640 & 0.6547 & 1 \\
\hline South Korea & -0.5598 & 0.9763 & 0 & -5.7232 & 0.0001 & 0 \\
\hline Spain & -3.0407 & 0.1341 & 1 & -1.9542 & 0.6082 & 1 \\
\hline Sweden & -2.2528 & 0.4491 & 1 & -3.6994 & 0.0342 & 3 \\
\hline Switzerland & -2.8179 & 0.1996 & 2 & -2.6868 & 0.2470 & 0 \\
\hline Turkey & -3.0091 & 0.1419 & 0 & -1.9779 & 0.5961 & 0 \\
\hline United Kingdom & -3.9468 & 0.0192 & 3 & -1.9628 & 0.6037 & 1 \\
\hline United States & -2.4501 & 0.3499 & 1 & -0.3351 & 0.9868 & 1 \\
\hline
\end{tabular}

